\title{
Prevalence and Antibiotic Resistance of Listeria monocytogenes Isolated from Ready-to-Eat Foods in Turkey
}

\author{
Pınar Şanlıbaba $\mathbb{D}^{1},{ }^{1}$ Başar Uymaz Tezel, ${ }^{2}$ and Gürcü Aybige Çakmak ${ }^{3}$ \\ ${ }^{1}$ Department of Food Engineering, Engineering Faculty, Ankara University, 50 ${ }^{\text {th }}$ Year Settlement, 06830 Gölbaşı, Ankara, Turkey \\ ${ }^{2}$ Çanakkale University, Bayramiç Vocational School, Food Technology Program, 17700 Bayramiç, Çanakkale, Turkey \\ ${ }^{3}$ Akdeniz University, Department of Food Engineering, Faculty of Engineering, 07058 Antalya, Turkey
}

Correspondence should be addressed to Pınar Şanlıbaba; sanlibab@ankara.edu.tr

Received 23 June 2018; Revised 7 September 2018; Accepted 24 September 2018; Published 14 October 2018

Academic Editor: Jorge Barros-Velázquez

Copyright (c) 2018 Pinar Șanlibaba et al. This is an open access article distributed under the Creative Commons Attribution License, which permits unrestricted use, distribution, and reproduction in any medium, provided the original work is properly cited.

\begin{abstract}
The aim of the present study was the determination of the prevalence and antibiotic resistance of L. monocytogenes in ready-to-eat (RTE) foods in Ankara, Turkey. In order to detect and isolate L. monocytogenes from 201 RTE food samples, the EN ISO 11290:1 method was used. All isolates were identified using the polymerase chain reaction. The strains were also confirmed by the detection of the hemolysin gene ( $h l y \mathrm{~A})$. The overall prevalence of $L$. monocytogenes was $8.5 \%$ among the food samples. Seventeen L. monocytogenes strains were examined by the disk diffusion assay for their resistance to 23 antibiotics. All strains were susceptible to erythromycin, clarithromycin, streptomycin, gentamicin, vancomycin, imipenem, trimethoprim, and chloramphenicol, while all strains were resistant to nalidixic acid, ampicillin, penicillin $\mathrm{G}$, linezolid, and clindamycin. The higher resistance was found against oxacillin (94.1\%), kanamycin (76.5\%), levofloxacin (70.6\%), and teicoplanin (64.7\%), followed by amoxicillin/clavulanic acid (53.0\%), rifampicin (47.1\%), and ciprofloxacin (35.3\%). A lower incidence of resistance was observed against tetracycline (5.9\%), meropenem (5.9\%), and trimethoprim/sulfamethoxazole (17.7\%). All isolates were multidrug resistant showing resistance to at least three antibiotic classes. High L. monocytogenes prevalence among analyzed RTE foods represents a high risk for public health. Our findings show a high prevalence of $L$. monocytogenes in RTE foods in Turkey. More effective control strategies for L. monocytogenes are needed to reduce both prevalence and resistance of L. monocytogenes in Turkish RTE foods.
\end{abstract}

\section{Introduction}

Listeria species include Gram-positive, facultatively anaerobic, psychrotrophic, rod-shaped, non-spore-forming bacteria [1]. Currently, the genus Listeria contains eighteen different species [2], of which $L$. monocytogenes and $L$. ivanovii are pathogenic, and the former is the major causative agent of listeriosis in human and other mammals [3]. Although the incidence of listeriosis is rarely encountered compared to illnesses caused by other food-borne pathogens such as Salmonella spp., Escherichia coli, or Campylobacter jejuni, it can be lethal for newborns, the elderly, immunocompromised individuals, and pregnant women $[4,5]$.
L. monocytogenes is highly prevalent in clinical and food samples due to its ability to grow over a wide range of temperature including refrigeration temperatures and $\mathrm{pH}$ as low as 4.4 , in high salinity $(40 \% \mathrm{w} / \mathrm{v})$, low water content, and hypoxic conditions $[5,6]$. L. monocytogenes is often found in soil, contaminated silage, and nontreated water and therefore can easily contaminate food products of both animal and plant origin [7]. An important source of L. monocytogenes infection is the consumption of processed readyto-eat (RTE) foods $[4,8]$, which provide a suitable medium for L. monocytogenes growth due to their long shelf life (one or more weeks) and low-temperature storage until consumption [9]. Furthermore, since RTE foods are consumed 
without further cooking, contaminating L. monocytogenes remain viable [10]. Many RTE food-born cases of listeriosis have been reported from all over the world. In March 2018, in South Africa, 978 people were infected with listeriosis, resulting in 674 hospitalizations and 183 deaths [11]. Another outbreak of listeriosis (20 cases) was reported in Australia by the World Health Organization (WHO) between January and April 2017, which resulted in the death of $35 \%$ of the patients [12]. European Food Safety Authority (EFSA) reported 1,763 confirmed cases of listeriosis from 27 member states, resulting in 191 deaths in 2013 [13]. In 2017, the Centers for Disease Control and Prevention (CDC) reported eight cases of listeriosis, after raw milk cheese consumption, resulting in two deaths [14]. In Turkey, foodborne listeriosis outbreaks have not been documented regularly, since they have not reached epidemic levels [15]. Although it is commonly detected in animals such as sheep and cattle, some food-borne listeriosis outbreaks have been reported in newborns and in cancer patients undergoing chemotherapy $[16,17]$. There are several regulations concerning the acceptable microbiological level of L. monocytogenes in RTE foods. In the United States, it is $0 \mathrm{CFU} / \mathrm{g}$ of L. monocytogenes per $25 \mathrm{~g}$ of the food sample. However, according to the European Commission (EC) regulations no. $2073 / 2005$ and no. 1441/2007, the number of L. monocytogenes should be less than $100 \mathrm{CFU} / \mathrm{g}$ in RTE products at the time of consumption. According to the Regulation $2073 / 2005$, RTE foods able to support the growth of $L$. monocytogenes must not present in $25 \mathrm{~g}$ of the sample before the food has left the immediate control of the food industry. Its population must not exceed the limit of $100 \mathrm{CFU} / \mathrm{g}$ throughout the shelf life [18, 19]. In Turkey, the Turkish Food Codex has stipulated that L. monocytogenes must not be detected at all in the RTE foods [20].

Since the isolation of the first multidrug-resistant $L$. monocytogenes strain in France in 1988, several strains isolated from food and environmental and clinical samples have shown resistance to one or more antibiotics $[5,21,22]$. The levels of resistance vary among the strains and are also influenced by antimicrobial use in humans and animals and geographical differences [23]. L. monocytogenes is usually susceptible to a wide range of antibiotics used against Grampositive bacteria. However, most strains of L. monocytogenes are naturally resistant to the currently used third and fourth generations fluoroquinolones and cephalosporins [22]. Genes conferring resistance to these drugs can successfully be transferred through movable genetic elements such as transposons and plasmids to other pathogenic bacteria. Common sources of resistance genes for L. monocytogenes are Enterococcus spp. and Staphylococcus spp. [24]. Moreover, increased exposure to biocides may select strains with high resistance to clinically relevant antibiotics [25]. The transmission of the resistant strains to humans via contaminated food products may have a serious impact on public health $[21,26]$.

So far very limited information is available on the prevalence of L. monocytogenes in RTE foods and their antimicrobial resistance in Turkey. Therefore, the objectives of this study were to (a) determine the prevalence of $L$. monocytogenes in RTE foods, (b) identify the isolated strains by phenotypic and genotypic methods, and (c) determine the resistance of these strains against 23 antibiotics. According to our knowledge, this is the first detailed study that explores the prevalence of L. monocytogenes in RTE foods in Turkey.

\section{Materials and Methods}

2.1. Sampling. Between March 2017 and June 2017, a total of 201 RTE food samples were randomly purchased from various supermarkets, restaurants, weekly open bazaars, and street hawkers in Ankara, Turkey. The RTE foods were classified into eleven categories, as shown in Table 1. The foods sold by the street hawkers were fresh and unpackaged, while those sold at the supermarkets were packaged and nonfrozen. All RTE foods taken from restaurants were high heat-treated products, except for salads and raw lettuce. The samples were checked for expiry dates and transported to the laboratory under aseptic and refrigerated conditions $\left(+4^{\circ} \mathrm{C}\right)$ on the sampling day and processed immediately.

\subsection{Isolation and Identification of Listeria monocytogenes.} The International Organization for Standardization (EN ISO, 11290-1) procedure with two-stage enrichment was used in this study. Briefly, $25 \mathrm{~g}$ of each food sample was first inoculated into $225 \mathrm{~mL}$ half Fraser broth (Merck ${ }^{\mathrm{TM}}$, Germany) for initial selective enrichment and homogenized in a stomacher (Seward 400, USA). After incubation at $30 \pm 1^{\circ} \mathrm{C}$ for $24 \pm 2 \mathrm{~h}, 0.1 \mathrm{~mL}$ of the broth culture was inoculated into $10 \mathrm{~mL}$ full-strength Fraser broth for second enrichment and cultured at $37^{\circ} \mathrm{C}$ for $48 \pm 2 \mathrm{~h}$. A loopful each of the half- and full-strength Fraser broths were plated on the chromogenic Listeria agar Ottaviani and Agosti (ALOA agar) (Merck ${ }^{\mathrm{TM}}$, Germany) and polymyxin acriflavine lithium chloride ceftazidime aesculin mannitol (PALCAM) agar (Merck ${ }^{\mathrm{TM}}$, Germany), and the plates were incubated at $37^{\circ} \mathrm{C}$ for $24-$ $48 \mathrm{~h}$. Five typical colonies each from ALOA and PALCAM agar were restreaked on tryptic soy agar supplemented with $0.6 \%$ of yeast extract (TSA-YE) $\left(\right.$ Sigma $^{\mathrm{TM}}$, Germany) as a nonselective medium and incubated at $37^{\circ} \mathrm{C}$ for $24-48 \mathrm{~h}$. The colonies from TSA-YE were verified by Gram staining, catalase reactions, oxidase tests, carbohydrate utilization, CAMP tests, and motility at $20-25^{\circ} \mathrm{C}$.

2.3. Bacterial Strains and Culturing. Listeria species isolated in this study and some reference strains (L. monocytogenes ATCC7644, L. innocua ATCC12612, L. seeligeri SLCC3945, L. welshimeri ATCC35897, Escherichia coli ATCC25922, and Staphylococcus aureus ATCC6538) were inoculated on tryptic soy broth supplemented with $0.6 \%$ of yeast extract (TSB-YE) (Sigma ${ }^{\mathrm{TM}}$, Germany) and brainheart infusion (BHI) broth (Merck ${ }^{\mathrm{TM}}$, Germany). The bacteria were grown at $35^{\circ} \mathrm{C}$ for $24 \mathrm{~h}$. The initial isolates from the food samples were stored at $-20^{\circ} \mathrm{C}$ with $30 \%(\mathrm{v} / \mathrm{v})$ glycerol (Merck ${ }^{\mathrm{TM}}$, Germany). The reference strains were obtained from the culture collection of Food 
TABle 1: Prevalence of Listeria species in RTE foods.

\begin{tabular}{|c|c|c|c|c|c|c|}
\hline \multirow{2}{*}{ Product } & \multirow{2}{*}{ Number of samples } & \multicolumn{5}{|c|}{ Number of positive samples (\%) } \\
\hline & & Listeria spp. & L. monocytogenes & L. innocua & L. welshimeri & L. seeligeri \\
\hline Cooked red meat product & 44 & $14(31.8)$ & $7(15.9)$ & $4(9.1)$ & $2(4.6)$ & $1(2.3)$ \\
\hline Cooked chicken product & 38 & $9(23.7)$ & $4(10.5)$ & $3(7.9)$ & $2(5.3)$ & $0(-)$ \\
\hline Seafood product & 25 & $7(28.0)$ & $3(12.0)$ & $2(8.0)$ & $2(8.0)$ & $0(-)$ \\
\hline Vegetarian product & 15 & $1(6.7)$ & $0(-)$ & $1(6.7)$ & $0(-)$ & $0(-)$ \\
\hline Raw lettuce & 15 & $0(-)$ & $0(-)$ & $0(-)$ & $0(-)$ & $0(-)$ \\
\hline Fruit salad & 13 & $0(-)$ & $0(-)$ & $0(-)$ & $0(-)$ & $0(-)$ \\
\hline Egg-based product & 12 & $1(8.3)$ & $0(-)$ & $0(-)$ & $1(8.3)$ & $0(-)$ \\
\hline Vegetable salad & 11 & $4(36.4)$ & $2(18.2)$ & $1(9.1)$ & $1(9.1)$ & $0(-)$ \\
\hline Dairy product & 10 & $3(30.0)$ & $1(10.0)$ & $2(20.0)$ & $0(-)$ & $0(-)$ \\
\hline Mayonnaise-based deli salad & 10 & $2(20.0)$ & $0(-)$ & $1(10.0)$ & $1(10.0)$ & $0(-)$ \\
\hline Desserts with milk & 8 & $0(-)$ & $0(-)$ & $0(-)$ & $0(-)$ & $0(-)$ \\
\hline Total & 201 & $41(20.4)$ & $17(8.5)$ & $14(7.0)$ & $9(4.5)$ & $1(0.5)$ \\
\hline CI $95 \%$ & & $11.4-21.2 \%$ & $5.08-12.81 \%$ & $3.67-12.65 \%$ & $3.40-6.38 \%$ & $0.201-2.914 \%$ \\
\hline
\end{tabular}

Microbiology Laboratory, Department of Food Engineering, Ankara University, Ankara, Turkey.

2.4. Molecular Identification. Following the biochemical tests, the presumptive isolates were confirmed by polymerase chain reaction (PCR) analysis. Genomic DNA was extracted from the bacterial cells grown at $35^{\circ} \mathrm{C}$ overnight in TSB-YE using a genomic DNA extraction kit (Thermo Fisher Scientific $\left.{ }^{\mathrm{TM}}\right)$, as per the manufacturer's instructions. The primer pairs designated as U1 (5'CAGCMGCCGCGGTAATWC- $\left.3^{\prime}\right)$ and LI1 (5'CTCCATAAAGGTGACCCT- $3^{\prime}$ ) were used to amplify a $938 \mathrm{bp}$ region in the $16 \mathrm{~S}$ rRNA gene of the Listeria genus [27]. In addition, the primer pairs $\mathrm{F}: 5^{\prime}-$ GCAGTTGCAAGCGCTTGGAGTGAA- $3^{\prime}$ and R: $5^{\prime}$ GCAACGTATCCTCCAGAGTGATCG-3' were used to amplify a $456 \mathrm{bp}$ region of the $h l y \mathrm{~A}$ gene of L. monocytogenes isolates [28]. Each $50 \mu \mathrm{L}$ PCR mixture contained $5 \mu \mathrm{L}$ PCR buffer, $1 \mu \mathrm{L} 2 \mathrm{mM}$ dNTP mix, $1 \mu \mathrm{L}$ of each primer, $34.75 \mu \mathrm{L}$ sterile distilled water, $0.25 \mu \mathrm{L}$ Taq DNA polymerase, $4 \mu \mathrm{L}$ of $25 \mathrm{mM} \mathrm{MgCl}_{2}$, and $3 \mu \mathrm{L}$ DNA template [29]. PCR amplification was carried out in a programmed ThermoCycler (Techne TC-512, Staffordshire, UK) with the following conditions: (1) initial hold of $2 \mathrm{~min}$ at $95^{\circ} \mathrm{C}$, (2) denaturation step at $95^{\circ} \mathrm{C} / 45 \mathrm{~s}$, annealing at $55^{\circ} \mathrm{C} / 45 \mathrm{~s}$, extension at $72^{\circ} \mathrm{C} / 2 \mathrm{~min}$, and (3) final extension step at $72^{\circ} \mathrm{C} / 7 \mathrm{~min}$. The PCR products were electrophoresed in $1 \%$ agarose gel, stained with ethidium bromide solution, and visualized under a UV illuminator (SYNGENE, Biosystems UK). The size of amplified fragments was determined by comparing with an O'Gene Ruler ${ }^{\mathrm{TM}} 10000$ bp DNA ladder (Thermo Scientific $\left.{ }^{\mathrm{TM}}\right)$.

2.5. Antibiotic Resistance Test. L. monocytogenes strains were tested for their resistance to different antibiotics with the disk diffusion method on Mueller-Hinton agar (Merck ${ }^{\mathrm{TM}}$, Germany) containing $0.5 \%$ defibrinated sheep blood, as described by the Clinical and Laboratory Standards Institute (CLSI) [30]. Penicillin G (10 $\mu \mathrm{g} / \mathrm{disc})$, oxacillin $(1 \mu \mathrm{g} / \mathrm{disc})$, ampicillin $(10 \mu \mathrm{g} / \mathrm{disc}), \quad$ amoxicillin/clavulanic acid (20/10 $\mu \mathrm{g} /$ disc), erythromycin (15 $\mu \mathrm{g} / \mathrm{disc})$, clarithromycin $(15 \mu \mathrm{g} / \mathrm{disc})$, tetracycline $(30 \mu \mathrm{g} / \mathrm{disc})$, ciprofloxacin $(5 \mu \mathrm{g} / \mathrm{disc})$, levofloxacin $(5 \mu \mathrm{g} / \mathrm{disc})$, nalidixic acid $(30 \mu \mathrm{g} / \mathrm{disc})$, linezolid $(30 \mu \mathrm{g} / \mathrm{disc})$, kanamycin $(30 \mu \mathrm{g} / \mathrm{disc})$, streptomycin $(300 \mu \mathrm{g} / \mathrm{disc})$, gentamicin $(120 \mu \mathrm{g} / \mathrm{disc})$, vancomycin $(30 \mu \mathrm{g} / \mathrm{disc})$, teicoplanin $(30 \mu \mathrm{g} / \mathrm{disc})$, meropenem $(10 \mu \mathrm{g} / \mathrm{disc})$, imipenem $(10 \mu \mathrm{g} / \mathrm{disc})$, clindamycin $(2 \mu \mathrm{g} / \mathrm{disc})$, trimethoprim $(5 \mu \mathrm{g} / \mathrm{disc})$, trimethoprim/sulfamethoxazole $(1.25 / 23.75 \mu \mathrm{g} / \mathrm{disc})$, chloramphenicol $(30 \mu \mathrm{g} / \mathrm{disc})$, and rifampicin $(5 \mu \mathrm{g} / \mathrm{disc})$ were used. These antibiotics were chosen for using or preferring in the veterinary and human medicine for treatment of listeriosis. After $24 \mathrm{~h}$ of incubation, the zones of inhibition were measured $(\mathrm{mm})$, and the strains were categorized as susceptible, intermediate, or resistant to specific antibiotics as per the criteria of CLSI [30]. The breakpoints of Staphylococcus species resistance were considered since no resistance criteria exist in the CLSI guidelines for Listeria susceptibility testing [31, 32]. E. coli ATCC25922, S. aureus ATCC6538, and L. monocytogenes ATCC7644 were used as reference strains.

2.6. Statistical Analysis. All statistical analyses were carried out using SPSS 16 package. The analysis of one-way variance (ANOVA) followed by Tukey's test was applied to determine the differences between the antibiotic resistance of $L$. monocytogenes strains. Statistical significance was set at $p<0.05$. 95\% CI values were carried out using the Bonett method.

2.7. Nucleotide Sequence Accession Numbers. The nucleotide sequences of the $16 \mathrm{~S}$ rRNA genes from 41 isolates of the present study were submitted and deposited to the GenBank.

2.8. Dendogram Construction Method. The sequences were aligned with the multiple sequence alignment by CLUSTALW, and the neighbour-joining method was used for the phylogenetic tree. 


\section{Results}

3.1. Detection of L. monocytogenes in RTE Foods. The presence of Listeria was identified in 41 (20.4\%) of the 201 RTE food samples (Table 1). The $16 \mathrm{~S}$ rRNA sequence analysis indicated the highest prevalence of L. monocytogenes $(8.5 \%$, $17 / 201)$ in the food samples, followed by L. innocua $(7.0 \%$, $14 / 201)$, L. welshimeri $(4.5 \%, 9 / 201)$, and L. seeligeri $(0.5 \%$, $1 / 201)$. The analysis of the $16 \mathrm{~S}$ rRNA sequence allowed separating the Listeria spp. isolates in six clusters. Cluster 1 was composed of 29 isolates. Eight isolates belonged to cluster 2. Finally, groups 3, 4, 5, and 6 included only one strain (Figure 1). Seventeen L. monocytogenes isolates were also screened for the virulence-associated $h l y \mathrm{~A}$ gene, and all strains showed a positive result. Using the neighbour-joining method, phylogenetic relationships of $17 \mathrm{~L}$. monocytogenes were allowed to group into two main clusters. Cluster 1 was composed of 15 isolates. Two isolates belonged to cluster 2 (Figure 2). L. monocytogenes was most frequently isolated from the cooked red meat products $(41.2 \%, 7 / 17)$, followed by cooked chicken products $(23.5 \%, 4 / 17)$, seafood products $(17.6 \%, 3 / 17)$, vegetable salads $(11.8 \%, 2 / 17)$, and dairy products $(5.9 \%, 1 / 17)$. However, it was not detected in the samples from the other six categories of RTE foods including mayonnaise-based deli salads, desserts with milk, egg-based products, vegetarian products, fruit salads, and raw lettuce.

3.2. Antibiotic Resistance. The results of antibiotic resistance tests according to CLSI [30] are summarized in Table 2. All 17 L. monocytogenes strains were resistant to nalidixic acid, ampicillin, penicillin G, linezolid, and clindamycin. Frequent resistance was seen against oxacillin $(94.1 \%, 16 / 17)$, kanamycin $(76.5 \%, 13 / 17)$, levofloxacin $(70.6 \%, 12 / 17)$, and teicoplanin $(64.7 \%, 11 / 17)$. Furthermore, resistance to amoxicillin/clavulanic acid (53.0\%, 9/17), rifampicin $(47.1 \%$, 8/17), ciprofloxacin (35.3\%, 6/17), and trimethoprim/sulfamethoxazole $(17.7 \%, 3 / 17)$ was also observed. Finally, one strain showed resistance against tetracycline and meropenem (5.9\%). In contrast, all strains were susceptible to erythromycin, clarithromycin, streptomycin, gentamicin, vancomycin, imipenem, trimethoprim, and chloramphenicol.

Multidrug resistance, i.e., resistance to three or more antimicrobial agents, was observed in all L. monocytogenes strains. However, only one isolate $(5.9 \%)$ was resistant to six antibiotics, and two (11.8\%) of the isolates were resistant to seven antibiotics. On the whole, 14 of 17 (82.8\%) L. monocytogenes strains showed resistance to more than seven antibiotics.

\section{Discussion}

4.1. Prevalence of L. monocytogenes. The overall prevalence of L. monocytogenes was $8.5 \%$ and was the most frequently isolated species from the products of animal origin. These products usually require several processing steps before consumption and may be contaminated with L. monocytogenes at the postprocessing stages, thereby reflecting poor hygienic practices in the preparation of these foods at the retail level. Previous studies in Turkey $[9,10,33]$ have reported occurrence of $L$. monocytogenes in RTE foods between $4 \%$ and $6.2 \%$. Our findings showed higher rate of occurrence than that reported in previous studies in Turkey. The isolation rate of L. monocytogenes strains in this study was consistent with that reported in other countries, i.e., 6.25\% in Ethiopia [3], 9.5\% in Italy [6], 6.1\% in Northern Greece [19], 8.1\% in Greece [34], 6.2\% in Spain [35], 6\% in Canada [36], 6.87\% in China [37], and 7.5\% in Thailand [38]. Other studies have reported significantly higher isolation rates of L. monocytogenes in RTE foods, such as $18.2 \%$ in Jordan [4], 24.4\% in Amman [5], 11.19\% in Uruguay [8], $11.4 \%$ in Malaysia [39], 22.72\% in Spain [40], and $32.3 \%$ in Iran [41].

L. monocytogenes was isolated from $41.2 \%$ of the RTE cooked red meat products in our study, which is also a higher rate than that reported by Lambertz et al. [7] (1.2\%), Yücel et al. [33] (6.4\%), Shi et al. [37] (6.5\%), Gomez et al. [40] (27.9\%), and Iannetti et al. [42] (1.66\%). The prevalence of L. monocytogenes among the RTE cooked chicken products was $23.5 \%$, which was also higher than that reported in previous studies, which ranged from $3.5 \%$ to $18.2 \%$ $[4,18,21,33,39]$. The prevalence of $L$. monocytogenes in the RTE seafood products in our study was $17.6 \%$, similar to that reported in Estonia (16.8\%) [43], higher than that reported in Ethiopia (6\%), Northern Greece (6.1\%), the United Kingdom (6.74\%), Columbia (5\%), and Malaysia (6.7\%) $[3,19,36,39,44]$ and lower than the prevalence documented in Belgium (23.9\%) [45] and Jordan (31.5\%) [46]. We may speculate that the reason for the high prevalence of $L$. monocytogenes in the RTE cooked red meat, chicken, and seafood products could be due to (a) inadequate heat treatment, (b) inadequate physical separation between the raw and cooked food areas, (c) poor sanitation, or (d) cross contamination during processing and handling. Vegetable salads were the only raw products contaminated by $L$. monocytogenes in our study, with a prevalence of $11.8 \%$. The isolation rate of $L$. monocytogenes in the vegetable salads was reported as 5.56\% in Brazil [22], 25.8\% in China [37], 4.1\% in Nigeria [47], 22.5\% in Malaysia [48], and $4.18 \%$ in Spain [49]. The presence of $L$. monocytogenes in the vegetable salads could be attributed to cross contamination and may occur during harvesting from the equipment, transport containers, or human handling. We did not detect $L$. monocytogenes in mayonnaise-based deli salads, desserts with milk, egg-based products, vegetarian products, fruit salads, and raw lettuce. L. monocytogenes can be controlled in these products by the appropriate implementation of good manufacturing practices (GMPs) and hazard analysis and critical control point (HACCP) systems.

4.2. Antibiotic Resistance. An increasing number of reports have been accumulated concerning the isolation of $L$. monocytogenes strains resistant to one or more antibiotics from food products, since 1988 [50]. Ampicillin, oxacillin, and penicillin are the most active $\beta$-lactams that inhibit the synthesis of bacterial cell wall peptidoglycan [51]. L. 


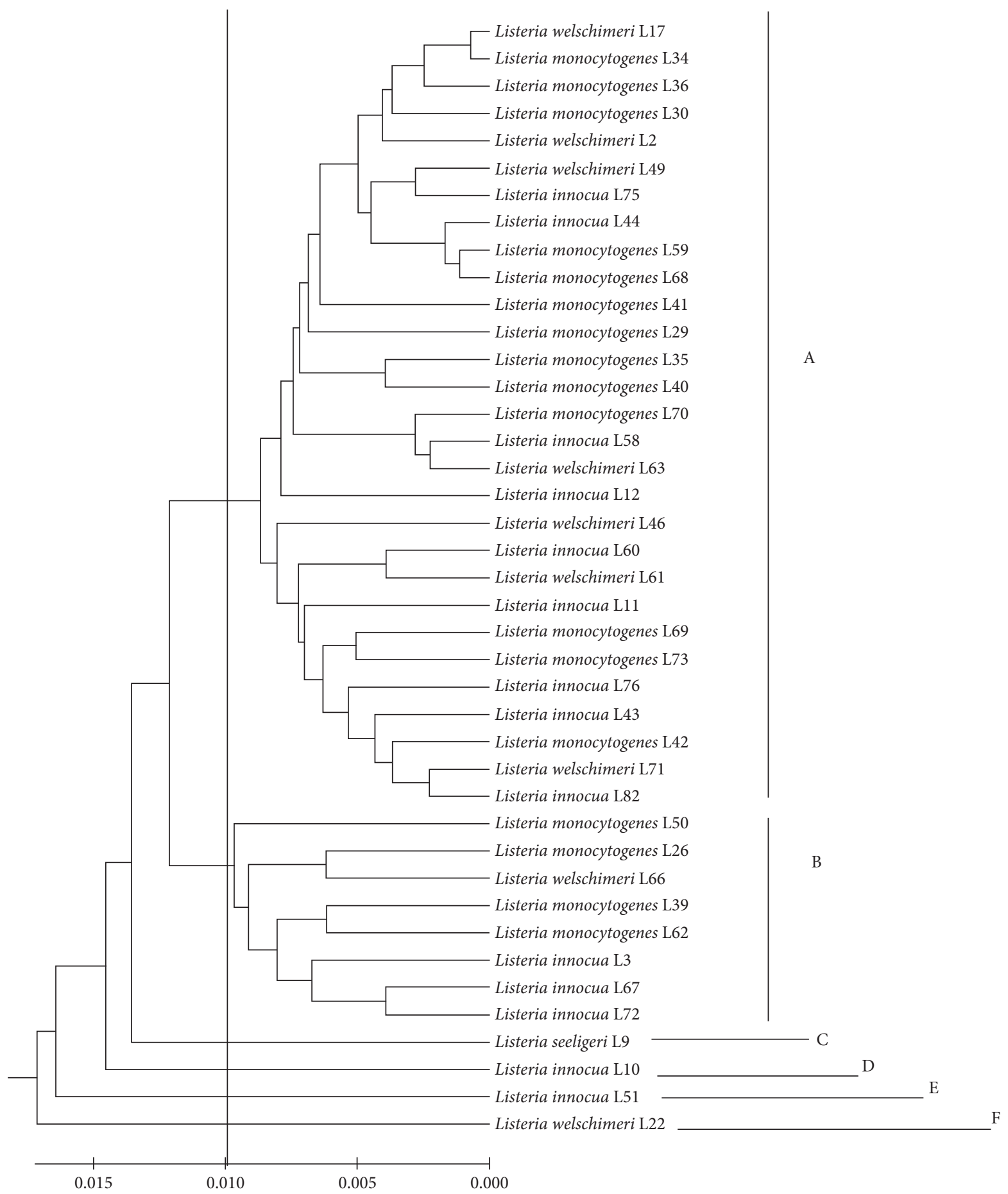

FIgURE 1: Dendrogram showing the evolutionary relationships among Listeria isolates based on the 16S rRNA sequence analysis.

monocytogenes is naturally susceptible to $\beta$-lactams, and the standard antibiotic therapy for human listeriosis includes penicillin/ampicillin alone or combined with an aminoglycoside (gentamicin) [5]. In the present study, all $L$. monocytogenes isolates from RTE foods displayed resistance to the $\beta$-lactam antibiotics, which is highly significant as far as the treatment of human listeriosis. The amoxicillin/clavulanic acid resistance was $53.0 \%$, which was higher than that reported by Ruiz-Bolivar et al. [24] but lower than that reported by Obaidat et al. [46] and Ennaji et al. [52]. Clavulanic acid is a nonantibiotic compound that can inhibit the beta-lactamase enzyme, thereby prolonging the antibacterial activity of amoxicillin [53]. The high level of resistance to oxacillin (94.1\%) observed in this study was similar to the findings of Khen et al. [31], Ieren et al. [47], and Gomez et al. [50]. Only one isolate of L. monocytogenes was resistant to tetracycline (5.9\%), which was significantly a lower rate than that reported by Garedew et al. [3] (37.5\%), 


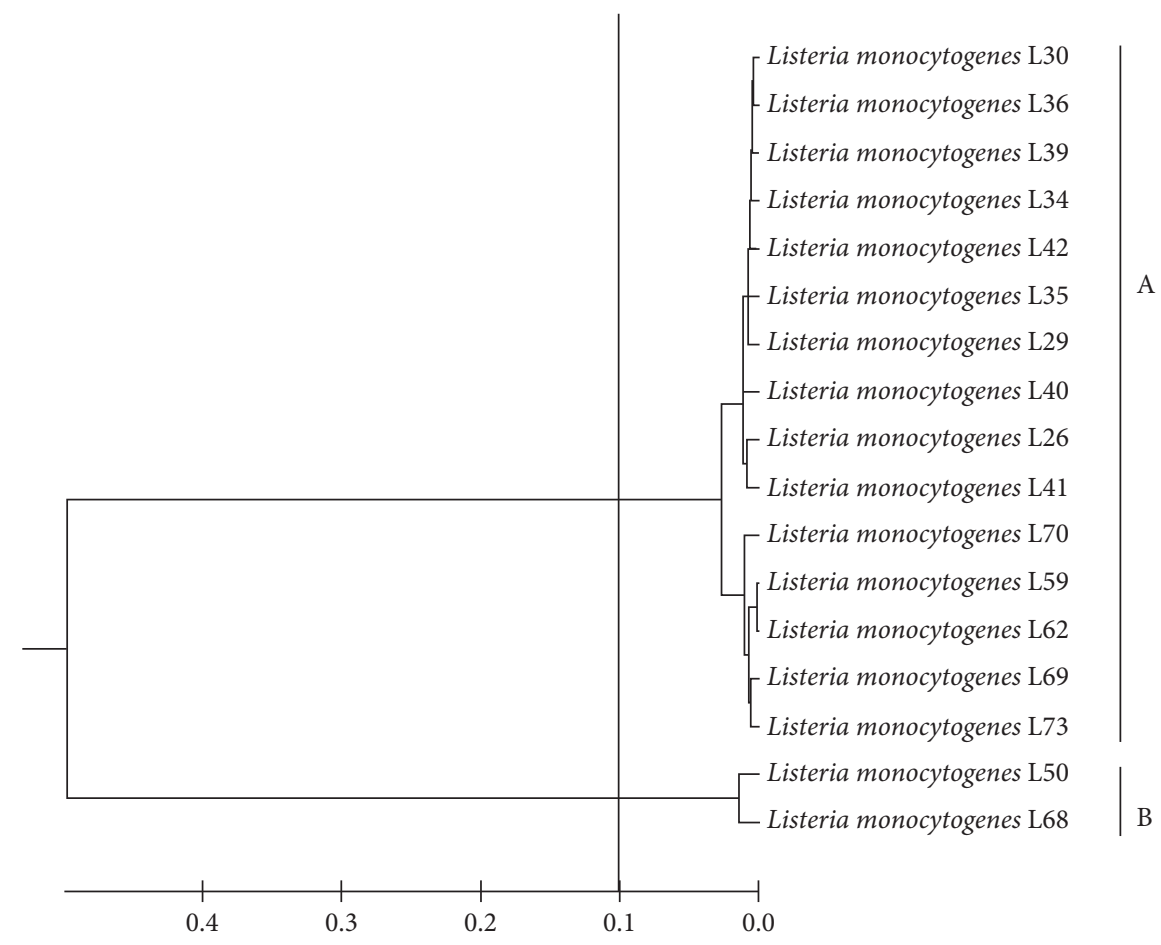

FIGURE 2: Dendrogram showing the evolutionary relationships among L. monocytogenes strains with the hlyA gene region.

Fallah et al. [21] (34.7\%), Wang et al. [26] (26.9\%), Jamali et al. [41] (27.9\%), and Obaidat et al. [46] (64.4\%). Tetracycline is not the primary drug for listeriosis treatment and is also not recommended for children and pregnant women [24]. All L. monocytogenes strains used in this study were resistant to nalidixic acid, which was similar to that reported by Ennaji et al. [52]. The resistance levels against ciprofloxacin $(35.3 \%)$ were higher in our study compared to the findings of Wilson et al. [54] (2\%), Kuan et al. [55] (5.2\%), and Noll et al. [56] (9.7\%). However, several studies have reported $100 \%$ susceptibility of L. monocytogenes to ciprofloxacin $[4,5,22,31,50,57]$. Since ciprofloxacin is not routinely used as a treatment option in listeriosis [54], the resistance of $L$. monocytogenes strains against this antibiotic is noncritical. We also observed $100 \%$ resistance to linezolid, which belongs to the oxazolidinones class of antibiotics that have a broad-spectrum activity against Gram-positive bacteria. It binds to the $23 \mathrm{~S}$ rRNA and disrupts the docking of the aminoacyl-tRNA in the A site of the ribosome and thus inhibits the delivery of peptides and the subsequent elongation of the polypeptide chain [51]. Contradictory to the findings of Wang et al. [26] and Shi et al. [37], none of the strains isolated in this study showed resistance against the aminoglycosides streptomycin and gentamicin that inhibit protein synthesis in bacteria by binding to one of the ribosomal subunits. However, $76.5 \%$ of the L. monocytogenes strains were resistant to kanamycin, in contrast to that reported by Al-Nabulsi et al. [5] (6.7\%), Jamali et al. [41] (4.8\%), and Obaidat et al. [46] (0\%). Although none of the $L$. monocytogenes strains were resistant to the glycopeptide vancomycin, $64.7 \%$ were resistant to teicoplanin, another antibiotic of the same class. Glycopeptides prevent cross- linking of peptidoglycan chains and inhibit cell wall synthesis. Vancomycin is used in treating L. monocytogenes bacteremia and endocarditis [46], and many studies [3, 5, 26] have reported the susceptibility of $L$. monocytogenes to vancomycin. However, other studies have reported 50\% [10], $74.8 \%$ [46], 57.1\% [47], and 20.9\% [58] prevalence of vancomycin-resistant $L$. monocytogenes strains. Only one strain was found to be resistant to meropenem (5.9\%) in our study, while none of the strains were resistant to imipenem. Meropenem has not been used in treating listeriosis in humans so far, and thus only a few studies have investigated meropenem resistance levels in $L$. monocytogenes strains $[24,55]$. Therefore, our results would be important as a reference in any future study on meropenem resistance among L. monocytogenes strains. Clindamycin, erythromycin, and chloramphenicol inhibit protein synthesis by preferential binding to the $50 \mathrm{~S}$ subunit of the bacterial ribosome. Although none of the strains were resistant to erythromycin and chloramphenicol in this study, $100 \%$ resistance was observed against clindamycin. Crossresistance is frequently observed among clindamycins $[24,59]$ and is attributed to the enzyme modifying the structure of clindamycin, which inactivates the antibiotic action, as previously reported by Ruiz-Bolivar et al. [24] and Jamali et al. [41]. All L. monocytogenes strains were susceptible to trimethoprim in our study, in accordance with the reports of Osaili et al. [4] and Ruiz-Bolivar et al. [24]. Trimethoprim is used for patients with penicillin sensitivity [46], and trimethoprim/sulfamethoxazole is generally used for the treatment of listeriosis in the patients allergic to penicillin [22]. In our study, $17.7 \%$ of the strains were resistant to trimethoprim/sulfamethoxazole. Although Ennaji 
TABle 2: Antibiotic susceptibility and resistance (\%) of L. monocytogenes strains isolated from RTE foods.

\begin{tabular}{|c|c|c|c|c|c|c|}
\hline \multirow{3}{*}{ Antimicrobial agent $\mathrm{t}^{\mathrm{a}}$} & \multicolumn{6}{|c|}{$\begin{array}{c}\text { Listeria monocytogenes strains } \\
(n: 17)\end{array}$} \\
\hline & \multicolumn{2}{|c|}{ S } & \multicolumn{2}{|c|}{ I } & \multicolumn{2}{|c|}{ R } \\
\hline & $n$ & $\%$ & $n$ & $\%$ & $n$ & $\%$ \\
\hline Penicillin G & $-^{c}$ & - & - & - & 17 & 100 \\
\hline Oxacillin & - & - & 1 & 5.9 & 16 & 94.1 \\
\hline Ampicillin & - & - & - & - & 17 & 100 \\
\hline Amoxicillin/clavulanic acid & 8 & 47.0 & - & - & 9 & 53.0 \\
\hline Erythromycin & - & - & 17 & 100 & - & - \\
\hline Clarithromycin & 8 & 47.0 & 9 & 53.0 & - & - \\
\hline Tetracycline & 16 & 94.1 & - & - & 1 & 5.9 \\
\hline Ciprofloxacin & - & - & 11 & 64.7 & 6 & 35.3 \\
\hline Levofloxacin & 1 & 5.9 & 4 & 23.5 & 12 & 70.6 \\
\hline Nalidixic acid & - & - & - & - & 17 & 100 \\
\hline Linezolid & - & - & - & - & 17 & 100 \\
\hline Kanamycin & - & - & 4 & 23.5 & 13 & 76.5 \\
\hline Streptomycin & 14 & 82.4 & 3 & 17.6 & - & - \\
\hline Gentamicin & 12 & 70.6 & 5 & 29.4 & - & - \\
\hline Vancomycin & 17 & 100 & - & - & - & - \\
\hline Teicoplanin & 1 & 5.9 & 5 & 29.4 & 11 & 64.7 \\
\hline Meropenem & 16 & 94.1 & - & - & 1 & 5.9 \\
\hline Imipenem & 17 & 100 & - & - & - & - \\
\hline Clindamycin & - & - & - & - & 17 & 100 \\
\hline Trimethoprim & 10 & 58.8 & 7 & 41.2 & - & - \\
\hline Trimethoprim/sulfamethoxazole & 10 & 58.8 & 4 & 23.5 & 3 & 17.7 \\
\hline Chloramphenicol & 17 & 100 & - & - & - & - \\
\hline Rifampicin & 1 & 5.8 & 8 & 47.1 & 8 & 47.1 \\
\hline
\end{tabular}

${ }^{a}$ The diameters of the zones were compared with the diameters of the Clinic Laboratory Standards Institute (CLSI 2011). ' S, susceptible; I, intermediate resistant; R, resistant. ${ }^{\mathrm{c}}$ Not detected.

et al. [52], Obaidat et al. [46], Fallah et al. [58], and Chen et al. [59] reported lower resistance to trimethoprim/sulfamethoxazole than our findings, Ieren et al. [47] reported higher incidence (57.1\%). Rifampicin is a wide-spectrum antibiotic that acts against Gram-positive bacteria by inhibiting the RNA polymerase $\beta$ subunit. It is commonly used against Mycobacterium tuberculosis when multidrug resistance is not detected [24]. The rifampicin resistance in our study was $47.1 \%$, which is higher than that reported in previous studies: $41 \%$ [24], 3.9\% [26], 4\% [31], $10 \%$ [37], $0.72 \%$ [58], and 5.2\% [60]. The higher levels of rifampicin resistance seen in our study could be clinically relevant.

In the present study, there was no significant association between the different $L$. monocytogenes strains in terms of antibiotic resistance $(p>0.05)$. To our knowledge, this is the first study in Turkey that reports $100 \%$ prevalence of multidrug resistance among $L$. monocytogenes strains isolated from RTE foods. In contrast to our findings, Chen et al. [59] did not determine multidrug resistance in L. monocytogenes strains. The geographical distribution of multiresistance patterns are as follows: $48.8 \%$ in Colombia [24], $60.2 \%$ in Iran [21], 57.7\% in China [26], 95.2\% in India [46], $64.3 \%$ in Nigeria [47], and $21 \%$ in Germany [56]. These differences may result from the regional use of antimicrobials.

\section{Conclusions}

Our findings showed a high prevalence of L. monocytogenes in RTE foods, which needs to be controlled in order to reduce the risk of listeriosis. Increasing antibiotic resistance among L. monocytogenes strains has been detected worldwide. This study is the first one to report multiple-drug resistance in $L$. monocytogenes strains isolated from RTE foods in Turkey, which is a public health concern. Our findings also show that RTE foods could be a reservoir for harboring multidrug-resistant $L$. monocytogenes strains.

\section{Data Availability}

The data used to support the findings of this study are included within the article.

\section{Conflicts of Interest}

The authors declare that there are no conflicts of interest associated with this work.

\section{Acknowledgments}

This work was supported by the Ankara University Scientific Research Projects Coordination Unit (Project Number 15B0443010). We thank Prof. Dr. Mustafa AKÇELIK (Ankara University) for supporting in the execution of this research.

\section{References}

[1] F. Akrami-Mohajeri, Z. Derakhshan, M. Ferrante et al., "The prevalence and antimicrobial resistance of Listeria spp. in raw milk and traditional dairy products delivered in Yazd (2016), central Iran," Food and Chemical Toxicology, vol. 114, pp. 141-144, 2018.

[2] The National Center for Biotechnology Information, 2018, https://www.ncbi.nlm.nih.gov/taxonomy/browser/wwwtax. cgi? id $=1637$.

[3] L. Garedew, A. Taddese, T. Biru et al., "Prevalence and antimicrobial susceptibility profile of Listeria species from ready-to-eat foods of animal origin in Gondor town, Ethiopia," BMC Microbiology, vol. 15, no. 1, p. 100, 2015.

[4] T. M. Osaili, A. R. Alaboudi, and E. A. Nesiar, "Prevalence of Listeria spp. and antibiotic susceptibility of Listeria monocytogenes isolated from raw chicken and ready-to-eat chicken products in Jordan," Food Control, vol. 22, no. 3-4, pp. 586590, 2011.

[5] A. A. Al-Nabulsi, T. M. Osaili, R. R. Shaker et al., "Effects of osmotic pressure, acid, or cold stresses on antibiotic susceptibility of Listeria monocytogenes," Food Microbiology, vol. 46, pp. 154-160, 2015.

[6] D. Meloni, P. Galluzzo, A. Murreddu et al., "Listeria monocytogenes in RTE foods marketed in Italy: prevalence and automated EcoRI ribotyping of the isolates," International Journal of Food Microbiology, vol. 129, no. 2, pp. 166-173, 2009.

[7] S. T. Lambertz, C. Nilsson, A. Bradenmark, S. Sylven, and A. Johansson, "Prevalence and level of Listeria monocytogenes in ready-to-eat foods in Sweden 2010," International Journal of Food Microbiology, vol. 160, no. 1, pp. 24-31, 2012. 
[8] V. Braga, S. Vazquez, V. Vico et al., "Prevalence and serotype distribution of Listeria monocytogenes isolated from foods in Montevideo-Uruguay," Brazilian Journal of Microbiology, vol. 48, no. 4, pp. 698-694, 2017.

[9] Z. Gürler, S. Pamuk, Y. Yildirim, and N. Ertas, "The microbial quality or ready-to-eat salads in Turkey: a focus on Salmonella spp. and Listeria monocytogenes," International Journal of Food Microbiology, vol. 196, pp. 79-83, 2015.

[10] G. Terzi, A. Gücükoğlu, Ö. Çadırcı, T. Uyanık, and M. Alişarlı, "Serotyping and antibiotic susceptibility of Listeria monocytogenes isolated from ready-to-eat foods in Samsun, Turkey," Turkish Journal of Veterinary and Animal Sciences, vol. 39, pp. 211-217, 2015.

[11] Situation Update on Listeriosis Outbreak, South Africa, 2018, http://www.nicd.ac.za/wp-content/uploads/2018/03/listeriasitrep-13mar2018_finalapproved.pdf.

[12] World Health Organization (WHO) Listeriosis-Australia, 2018, http://www.who.int/csr/don/09-april-2018-listeriosisaustralia/en/.

[13] A. Ricci, A. Allende, D. Bolton et al., "Listeria monocytogenes contamination of ready-to-eat foods and the risk for human health in the EU," EFSA Journal, vol. 16, no. 1, p. 5134, 2018.

[14] CDC, Multistate Outbreak of Listeriosis Linked to Soft Raw Milk Cheese Made by Vulto Creamery (Final Update), 2018, https://www.cdc.gov/listeria/outbreaks/soft-cheese-03-17/ index.html.

[15] M. Yavuz and M. Korukluoğlu, "Listeria monocytogenes'in gidalardaki önemi ve insan sağlığı üzerine etkileri,” Journal of Agricultural Faculty of Uludag University, vol. 24, no. 1, pp. 1-10, 2010.

[16] N. Ağuş, N. Yilmaz, S. S. Medeni, L. Kuzucu, and N. Akgure, "Sepsis due to Listeria monocytogenes: a case report," Ankem Dergisi, vol. 27, no. 2, pp. 80-82, 2013.

[17] F. Tekay, E. Özbek, E. Kazanc1 et al., "A case of neonatal sepsis due to Listeria monocytogenes serotype $4 \mathrm{~b}$ : case report and literature review," Dicle Medical Journal, vol. 41, no. 3, pp. 599-602, 2014.

[18] S. S. Awaisheh, "Incidence and contamination level of Listeria monocytogenes and other Listeria spp. in ready-to-eat meat products in Jordan," Journal of Food Protection, vol. 73, no. 3, pp. 535-540, 2010.

[19] N. Soultos, E. Iossifidou, Z. Tzikas et al., "Prevalence of Listeria monocytogenes in ready-to-eat seafood marketed in Thessaloniki (Northern Greece)," Veterinary World, vol. 7, no. 11, pp. 1004-1009, 2014

[20] Turkish food codex microbiological criteria regulation, Official Newspaper. Number: 28157, 2011.

[21] A. A. Fallah, S. S. Saei-Dehkordi, M. Rahnama, H. Tahmasby, and M. Mahzounieh, "Prevalence and antimicrobial resistance patterns of Listeria species isolated from poultry products marketed in Iran," Food Control, vol. 28, no. 2, pp. 327-332, 2012.

[22] V. V. Byrne, E. Hofer, D. C. Vallim, and R. C. C. Almeida, "Occurrence and antimicrobial resistance patterns of Listeria monocytogenes isolated from vegetables," Brazilian Journal of Microbiology, vol. 47, no. 2, pp. 438-443, 2016.

[23] D. Korsak, A. Borek, S. Daniluk, A. Grabowska, and K. Pappelbaum, "Antimicrobial susceptibilities of Listeria monocytogenes strains isolated from food and food processing environment in Poland," International Journal of Food Microbiology, vol. 158, no. 3, pp. 203-208, 2012.

[24] Z. Ruiz-Bolivar, M. Neuque-Rico, R. Poutou-Pinales, A. K. Carrascal-Camacho, and S. Mattar, "Antimicrobial susceptibility of Listeria monocytogenes food isolates from different cities in Colombia," Foodborne Pathogens and Disease, vol. 8, no. 8, pp. 913-919, 2011.

[25] J. Barbosa, R. Magalhaes, I. Santos et al., "Evaluation of antibiotic resistance patterns of food and clinical Listeria monocytogenes isolates in Portugal," Foodborne Pathogens and Disease, vol. 10, no. 10, pp. 861-866, 2013.

[26] K. Wang, K. Ye, Y. Zhu, Y. Huang, G. Wang, and H. Wang, "Prevalence, antimicrobial resistance and genetic diversity of Listeria monocytogenes isolated from chilled pork in Nanjing, China," LWT-Food Science and Technology, vol. 64, no. 2, pp. 905-910, 2015.

[27] U. B. Usman, J. K. P. Kwaga, J. Kabir, and O. S. Olonitola, "Isolation and antimicrobial susceptibility of Listeria monocytogenes from raw milk and milk products in northern Kaduna state, Nigeria," Journal of Applied and Environmental Microbiology, vol. 4, no. 3, pp. 46-54, 2016.

[28] B. Paziak-Domanska, E. Bogulawska, M. Wiekowska-Szakiel et al., "Evaluation of the API test, phosphatidylinositolspecific phospholipase C activity and PCR method in identification of Listeria monocytogenes in meat foods," FEMS Microbiological Letters, vol. 171, no. 2, pp. 209-214, 1999.

[29] G. Blaiotta, O. Pepe, G. Mauiello et al., "16S-23S rDNA intergenic spacer region polymorphism of Lactococcus gavriae, Lactococcus raffinolactis and Lactococcus lactis as revealed by PCR and nucleotide sequence analysis system," Applied and Environmental Microbiology, vol. 25, no. 4, pp. 520-527, 2002.

[30] CLSI, Performance Standards for Antimicrobial Susceptibility Testing: Twenty-First Informational Supplement, Clinical and Laboratory Standards Institute, M100-S21, Wayne, PA, USA, 2011.

[31] B. K. Khen, O. A. Lynch, J. Carroll, D. A. Mcdowell, and G. Duffy, "Occurrence, antibiotic resistance and molecular characterization of Listeria monocytogenes in the beef chain in the republic of Ireland," Zoonoses and Public Health, vol. 62, pp. 11-17, 2014.

[32] X. J. Du, X. Zhang, X. Wang et al., "Isolation and characterization of Listeria monocytogenes in Chinese food obtained from the central area of China," Food Control, vol. 74, pp. 9-16, 2017.

[33] N. Yücel, S. Çıtak, and M. Önder, "Prevalence and antibiotic resistance of Listeria species in meat products in Ankara, Turkey," Food Microbiology, vol. 22, no. 2-3, pp. 241-245, 2005.

[34] A. S. Angelidis and K. Koutsoumanis, "Prevalence and concentration of Listeria monocytogenes in sliced ready-to-eat meat products in the Hellenic retail market," Journal of Food Protection, vol. 69, no. 4, pp. 938-942, 2006.

[35] V. Garrido, A. I. Vitas, and I. Garcia-Jallon, "Survey of Listeria monocytogenes in ready-to-eat products: prevalence by brands and retail establishments for exposure assessment of listeriosis in Northern Spain," Food Control, vol. 20, no. 11, pp. 986-991, 2009.

[36] J. Kovacevic, L. McIntyre, S. B. Henderson, and T. Kosatsky, "Occurrence and distribution of Listeria species in facilities producing ready-to-eat foods in British Columbia, Canada," Journal of Food Protection, vol. 75, no. 2, pp. 216-224, 2012.

[37] W. Shi, W. Qingping, Z. Jumei, C. Moutong, and Y. Zean, "Prevalence, antibiotic resistance and genetic diversity of Listeria monocytogenes isolated from retail ready-to-eat foods in China," Food Control, vol. 47, pp. 340-347, 2015.

[38] K. Vongkamjan, J. Fuangpaiboon, M. P. Turner, and V. Vuddhakul, "Various ready-to-eat products from retail stores linked to occurrence of diverse Listeria monocytogenes 
and Listeria spp. isolates," Journal of Food Protection, vol. 79, no. 2, pp. 239-245, 2016.

[39] H. Jamali, L. C. Chai, and K. L. Thong, "Detection and isolation of Listeria spp. and Listeria monocytogenes in ready-toeat foods with various selective culture media," Food Control, vol. 32, no. 1, pp. 19-24, 2013.

[40] D. Gomez, L. P. Iguacel, M. C. Rota et al., "Occurrence of Listeria monocytogenes in ready-to-eat meat products and meat processing plants in Spain," Foods, vol. 4, no. 4, pp. 271-282, 2015.

[41] H. Jamali, M. Paydar, S. Ismail et al., "Prevalence, antimicrobial susceptibility and viral typing of Listeria species and Listeria monocytogenes isolated from open-air fish markets," BMC Microbiology, vol. 15, no. 1, p. 144, 2015.

[42] L. Iannetti, A. Acciari, S. Antoci et al., "Listeria monocytogenes in ready-to-eat foods in Italy: prevalence of contamination at retail and characterisation of strains from meat products and cheese," Food Control, vol. 68, pp. 55-61, 2016.

[43] T. Kramarenko, M. Roasto, R. Keto-Timonen et al., "Listeria monocytogenes in ready-to-eat vacuum and modified atmosphere packaged meat and fish products of Estonian origin at retail level," Food Control, vol. 67, pp. 48-52, 2016.

[44] R. J. Meldrum, P. W. Ellis, P. T. Mannion, D. Halsteaas, and J. Garside, "Prevalence of Listeria monocytogenes in ready-toeat foods sampled from point of sale in Wales, United Kingdom," Journal of Food Protection, vol. 73, no. 8, pp. 1515-1518, 2010.

[45] E. V. Coillie, H. Werbrouck, M. Heydrickx, L. Herman, and N. Rijpens, "Prevalence and typing of Listeria monocytogenes in ready-to-eat food products on the belgian market," Journal of Food Protection, vol. 67, no. 11, pp. 2480-2487, 2004.

[46] M. M. Obaidat, A. E. B. Salman, S. Q. Lafi, and A. R. AlAbboodi, "Characterization of Listeria monocytogenes from three countries and antibiotic resistance differences among countries and Listeria monocytogenes serogroups," Letters in Applied Microbiology, vol. 60, no. 6, pp. 609-614, 2015.

[47] I. I. Ieren, M. Bello, and J. K. P. Kwga, "Occurrence and antibiotic resistance profile of Listeria monocytogenes in salad vegetables and vegetable salads sold in Zaria, Nigeria," African Journal of Food Science, vol. 7, no. 9, pp. 334-338, 2013.

[48] J. Ponniah, T. Robin, M. S. Paie et al., "Listeria monocytogenes in raw salad vegetables sold at retail level in Malaysia," Food Control, vol. 21, no. 5, pp. 774-778, 2010.

[49] L. Z. Moreno, R. Paixao, D. D. Gobbi et al., "Characterization of atypical Listeria innocua isolated from swine slaughterhouses and meat markets," Research in Microbiology, vol. 163, no. 4, pp. 268-271, 2012.

[50] D. Gomez, E. Azon, N. Marco, J. J. Carraminana, and C. Rota, "Antimicrobial resistance of Listeria monocytogenes and Listeria innocua from meat products and meat-processing environment," Food Microbiology, vol. 42, pp. 61-65, 2014.

[51] W. R. Miller, J. M. Munita, and C. A. Arias, "Mechanisms of antibiotic resistance in enterococci," Expert Review of AntiInfective Therapy, vol. 12, no. 10, pp. 1221-1236, 2014.

[52] H. Ennaji, M. Timinouni, M. M. Ennaji, M. Hassar, and N. Cohen, "Characterization and antibiotic susceptibility of Listeria monocytogenes isolated from poultry and red meat in Morocco," Infection and Drug Resistance, vol. 2008, no. 1, pp. 45-50, 2008.

[53] E. Etebu and I. Arikekpar, "Antibiotics: classification and mechanisms of action with emphasis on molecular perspectives," International Journal of Applied Microbiology and Biotechnology Research, vol. 4, pp. 90-101, 2016.
[54] A. Wilson, J. Gray, P. S. Chandry, and E. M. Fox, "Phenotyping and genotyping analysis of antimicrobial resistance among Listeria monocytogenes isolated from Australian food production chains," Genes, vol. 9, no. 2, p. 80, 2018.

[55] C. H. Kuan, Y. Rukayadi, S. H. Ahmad et al., "Antimicrobial resistance of Listeria monocytogenes and Salmonella enteritidis isolated from vegetable farms and retail markets in Malaysia," International Food Research Journal, vol. 24, no. 4, pp. 1831-1839, 2017.

[56] M. Noll, S. Kleta, and S. A. Dahouk, “Antibiotic susceptibility of 259 Listeria monocytogenes strains isolated from food, foodprocessing plants and human samples in Germany," Journal of Infection and Public Health, vol. 11, no. 4, pp. 572-577, 2018.

[57] S. S. Chemben and D. Puchooa, "Isolation and characterization of Listeria species from ready-to-eat raw pork sausages processed in Mauritius," Asian Journal of Agriculture and Food Sciences, vol. 3, no. 3, pp. 312-320, 2015.

[58] A. A. Fallah, S. S. Saei-Dehkordi, and M. Mahzounieh, "Occurrence and antibiotic resistance profiles of Listeria monocytogenes isolated from seafood products and market and processing environments in Iran," Food Control, vol. 34, no. 2, pp. 630-636, 2013.

[59] B. Y. Chen, R. Pyle, T. J. Kim, J. L. Silva, and Y. S. Jung, "Antibiotic resistance in Listeria species isolated from catfish fillets and processing environment," Letters in Applied Microbiology, vol. 50, no. 6, pp. 626-632, 2010.

[60] N. Kocaman and B. Sarımehmetoğlu, "Isolation of Listeria monocytogenes in lamb meat and determination of the antibiotic resistance," Ankara Üniversitesi Veterinerlik Fakültesi Dergisi, vol. 64, no. 4, pp. 273-279, 2017. 


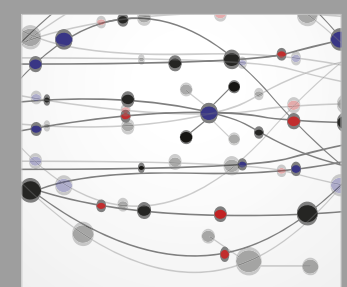

The Scientific World Journal
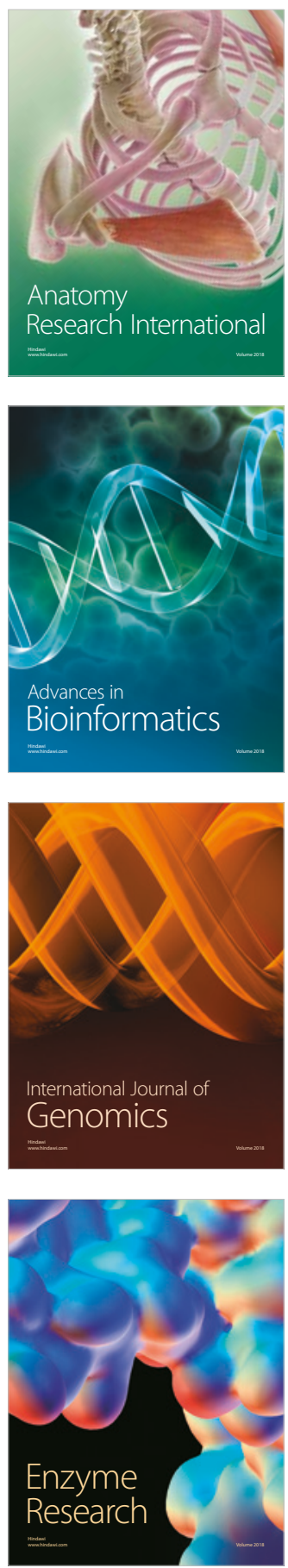
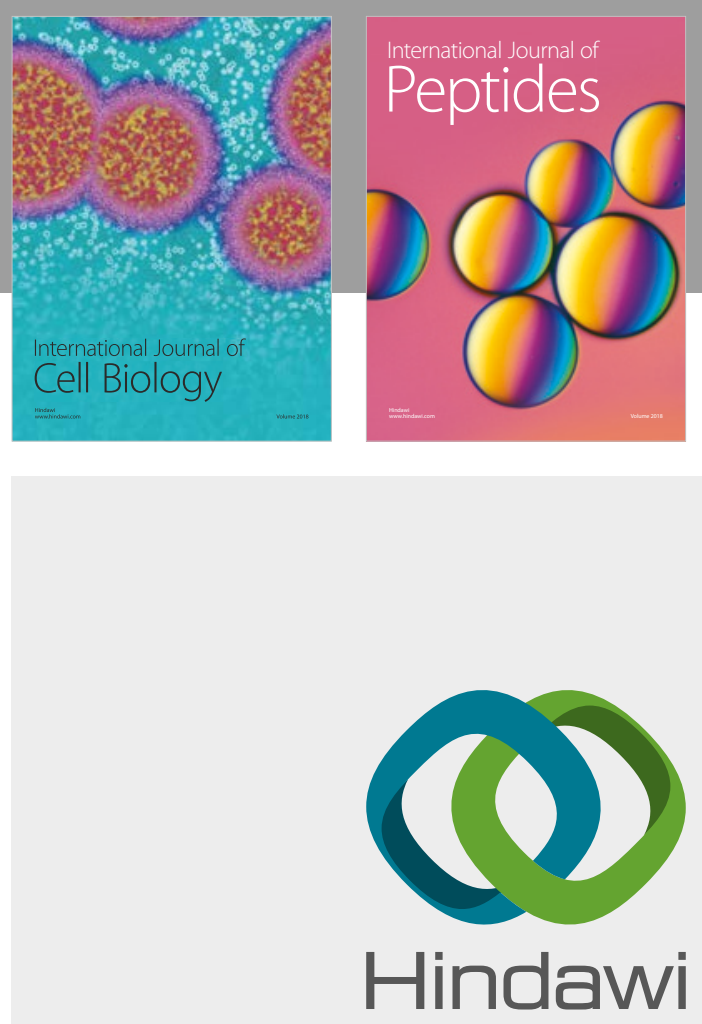

Submit your manuscripts at

www.hindawi.com
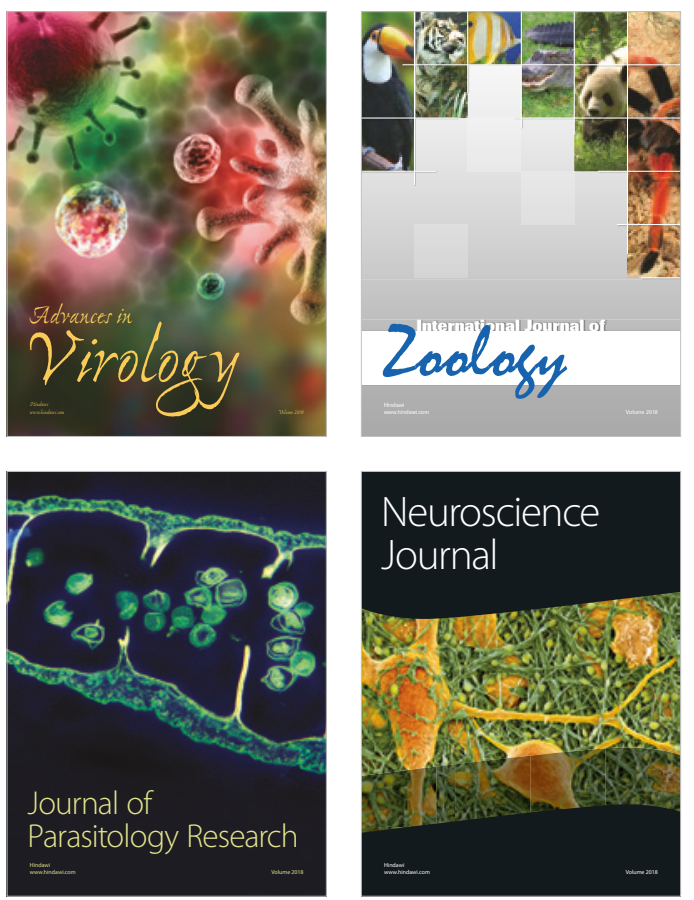
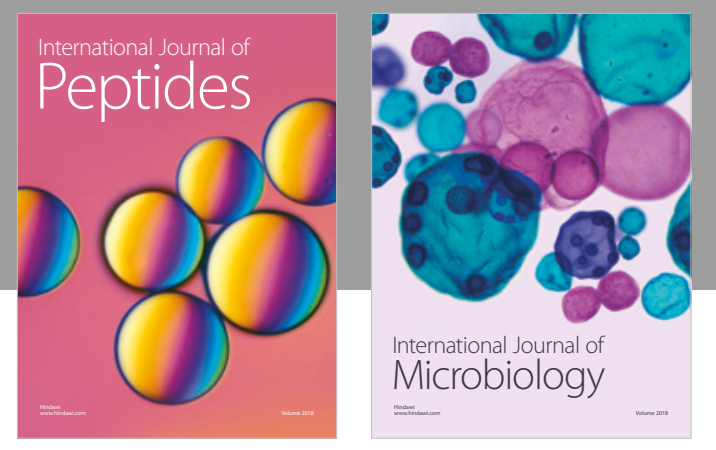

nternational Journal of Microbiology
Journal of
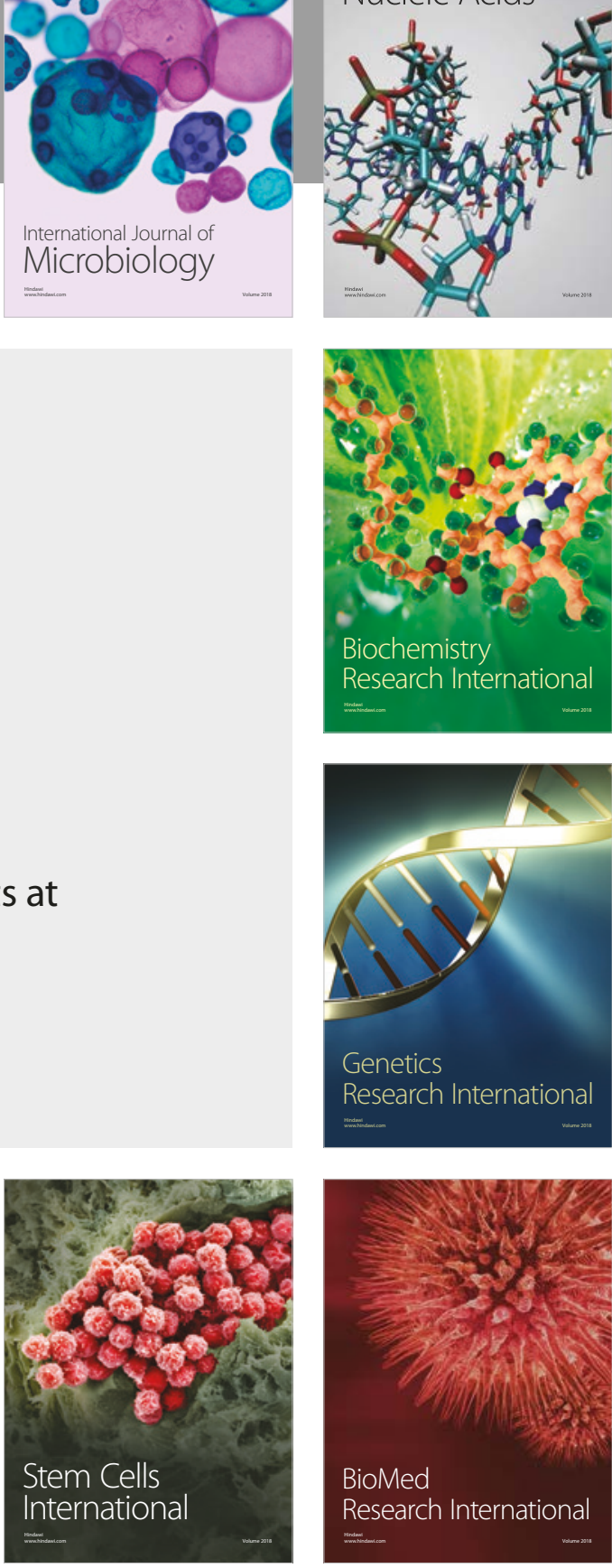
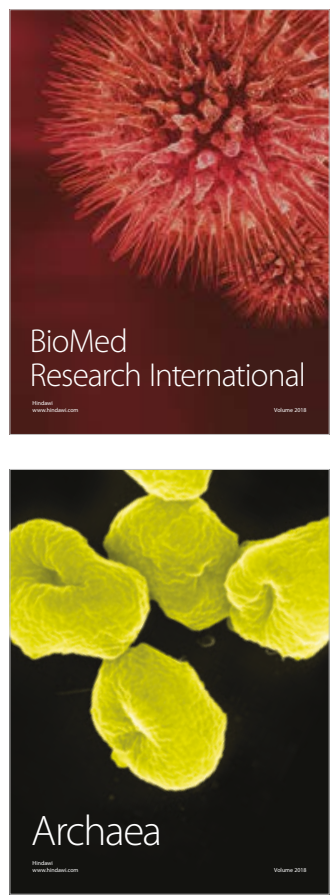